\title{
The Opinions of Persons with Hearing Impairment on the Help of Assistive Devices - Hearing Aids
}

M. Marak (Marian Marak), ${ }_{1}^{1}$ P. Beno (Pavol Beno)²

${ }^{1}$ Faculty of Social Sciences, University of ss. Cyril and Methodius in Trnava, SK

${ }^{2}$ Faculty of Health Care and Social Work, The University of Trnava, SK

\section{E-mail address:}

maros.marak@gmail.com

\section{Reprint address:}

Marian Marak

University of ss. Cyril and Methodius in Trnava

Faculty of Social Sciences

Bucianska 4/A

91701 Trnava

SK

Source: Clinical Social Work and Health Intervention

Volume: 9

Issue: 1

Pages: $60-66$

Cited references: 8

\section{Reviewers:}

Andrea Pokorna

Masaryk University, Brno, CZ

Jana Boronova

University of Trnava, SK

\section{Key words:}

Assistive Aid. Hearing Impairment. Communication Barriers.

\section{Publisher:}

International Society of Applied Preventive Medicine i-gap

CSWHI 2018; 9(1): 60 - 66; DOI 10.22359/cswhi_9_1_09 @ 2018 Clinical Social Work and Health Intervention

\section{Abstract:}

Introduction: The article deals with reviews and ratings of people with hearing impairments, measuring the effectiveness of hearing aids in facilitating communication with the surrounding world of hearing majority. It outlines the importance of assistive aids based on the partial 
results of the research that relates to the elimination of communication barriers of people with hearing disability.

Methodology and materials: The article presents partial results of the research for which a custom questionnaire was designed, according to a model of the International Classification of Functioning, Disability and Health - ICF. This classification, as opposed to ICD-10, takes into account the consequences of the diagnosis in the social environment. It monitors not only the state of health but also individual differences of the impact of hearing impairment on the quality of life. The research explores the importance of using a hearing aid in communication, compares the quality of speech recognition with and without using the assistive aid. Also, it focuses on the ability to talk with more people, and to what extent people with hearing impairment have difficulty listening to lectures or radio without a hearing aid.

Discussion: Based on the results, we concluded that hearing aids cannot restore the hearing ability as we know it in hearing people. Therefore, the assumption of the hearing majority that hearing-impaired people need no further intervention after being given a hearing aid, is incorrect. Generally, it cannot be argued that hearing aids are really providing effective support in elimination communication barriers in persons with high hearing loss.

Conclusion: People with high hearing loss do not usually use hearing aids as they are no longer helpful to them, and people, whom we refer to as "hard of hearing", do not suffer from hearing loss at the level that the criteria of the Social Welfare Law would recognize as eligible for allowance for higher quality hearing aids.

\section{Introduction}

The World Health Organization (WHO) reports that there is one child with complete hearing loss and 3 - 6 with hearing impairment in 1,000 newborn babies. The WHO also points out that the number of people with hearing disabilities in the world is growing (Tarcsiova, Hovorkova 2002). According to Slowik (2007) a person receives $60 \%$ of the information from the environment both in a targeted and involuntary manner. Beno (2014) in his publications broadly categorizes the implications of a hearing disability in terms of a communication barrier which brings along other problems. According Cernanova (2012) who is a Psychiatric Clinical Practitioner and deals with mental disorders due to hearing impairment, hearing disorder due to adverse impact on communication and thus on the interaction with the environment, causes many negative psychological and social effects. According to a study published by K. Tambs (2004) to which Cernanova (2012) refers, hearing-impaired people compared to general population suffer from higher levels of psychological distress; lower levels of social functioning; less common social activities; more relationship problems with family, friends and at work; greater emotional problems; increased anxiety; depression; phobias; and higher levels of interpersonal sensitivity and hostility. 
The common majority population assumes that the problems of the hearing impaired can be resolved by wearing a hearing aid which today is one of the best-known audio-prosthetic device. But in fact, hearing aids cannot restore hearing ability as it is known by hearing people. Therefore, the assumption that the hearing-impaired need no further intervention after being given a hearing aid, is incorrect. Groma (2009) points out that the acquired disorder needs much more than mere allocation and setup of a hearing aid. He also mentions rehabilitation and especially adaptation. He further states that "the problem of adaptation to hearing loss is underestimated in our circumstances." However, any state aid to those with hearing impairments whose hearing loss is less than $80 \%$ according to Fowler is also underestimated.

In our article, we describe selected results of research focused on the social policy of the state towards people with hearing impairments which maps the views of respondents to questions about the possibility of eliminating barriers in the field of communication. The questions in the research were prepared by a model of the International Classification of Functioning, Disability and Health (ICF). This classification is part of a set of classifications of the World Health Organization and is intended to measure and assess the degree of disability, medical fitness assessment, or for example, to identify specific educational needs. It is a multipurpose classification that serves different disciplines and sectors. Unlike the ICD-10 classification which only establishes a clinical diagnosis the ICF describes the more complex situation of people in terms of their health and their functional capabilities.

\section{Methodology and Materials}

We have also applied the model of functional disabilities and health capabilities in our research. We have created a custom questionnaire with questions and alternative options/responses that correspond to the original ICF questions. We have focused on those that are specific to communication and social assistance. 76 respondents (aged 24 and 72, mean age 44.21) who have a hearing disability participated in the survey so far. The respondents included 46 (61\%) women and 29 (39\%) men. Hearing loss reported by respondents ranged from $60 \%$ to $100 \%$ according to Fowler (Annex in Slovak Act 447/2008 Coll). When asked what assistive devices they use, most of them mentioned a hearing aid and only two the cochlear implant. That is why in our research we have also focused on the benefits of or the barriers in using this most common assistive device - the hearing aid.

The current market for assistive aids offers a great choice. From inexpensive in commercially focused sales to high-quality and expensive equipment from recognized companies. Hearing-impaired people choose them based on the type and nature of their own disability. In addition to the different types and shapes of these devices, their functions are particularly important. Currently, digital programmable devices are produced, but cheaper analog devices are still available on the market. The difference between them lies in the fact that digital devices are equipped with a chip that can detect whether the sound comes from the noise of environment or speech. They can suppress noise and adjust speech so that the sound is pure, amplified and minimally distorted.

Multi-channel devices can be tuned more precisely to individual frequencies, ensuring even better reception for people with different degrees of hearing loss. There are different settings for perceptual (sensorineural) types of disorder and for conductive types of disorder. Such a device can amplify the weakest sounds the most, 
the moderate ones less, and do not amplify too loud sounds at all. This is a great advantage over older devices that used to amplify all kinds of sounds equally. Today, there is no significant justification for using the older type of hearing aids by people with the sensorineural hearing impairment who have a greater problem with decryption of phonemes as well as volume. Hearing aids that are currently available as partly reimbursed by the insurance company are mostly cheaper analog devices and expensive programmable devices are less available for people with hearing impairment and there- that the hearing aid would be of significant help to them. Total difficulties without the assistive device were reported by almost half of the respondents (49.30\%). Even with the use of the device, total difficulties were still reported by $22.70 \%$ of the respondents. Based on the answers, we assume that the part of the respondents who experience great and total difficulties will move to the category of mild and moderate difficulty when using the device. This confirms the incorrect assumption of the hearing majority that once the hearing aid is in place, the affected person can hear well again.

Figure 1: Difficulty of listening / use of assistive aids $(N=75)$.

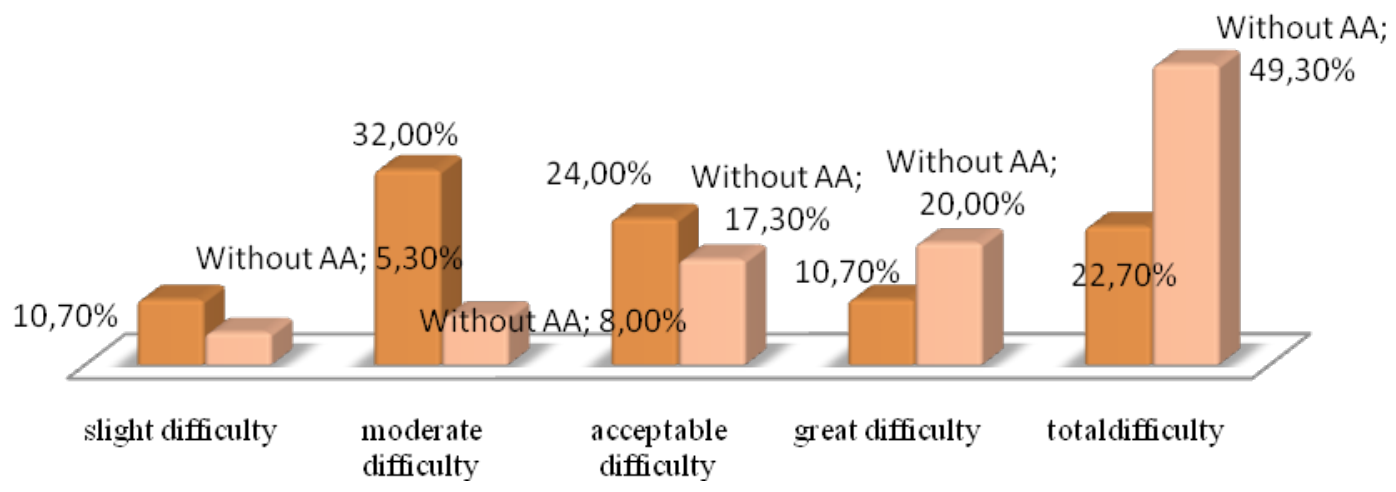

Source: Authors' own research

fore do not contribute to the elimination of communication barriers as it is generally expected.

\section{Results and Discussion}

Figure 1 shows the answers of respondents to a question about the difficulty of listening to radio, music or lectures with and without using assistive device (CD), i.e. the hearing aid. If we overlook the mean option of an alternative response which is often chosen by indecisive respondents the answers of respondents have not suggested
Figure 2 shows the answers of respondents to the question on the extent of help provided by a hearing aid. $41.4 \%$ of respondents said that the help is poor. More than half of them $(22 \%)$ said that the hearing aids "do not help at all". Positive-oriented responses offered a percentage of $38.70 \%$. We can conclude that most respondents also confirmed the opinion of the previously mentioned author, Groma (2009), who says that "the mere allocation of the aid is not enough". 
Figure 2: Use of assistive devices.

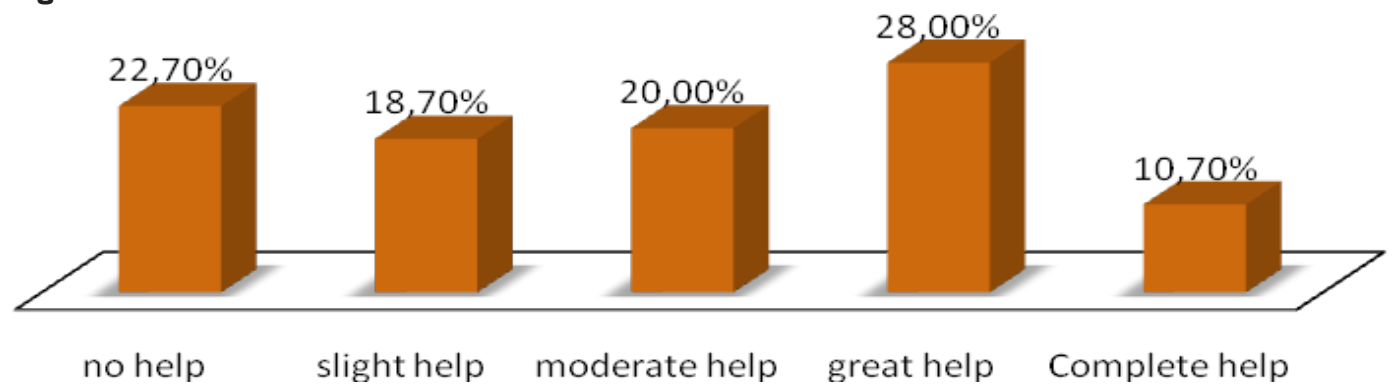

Source: Authors' own research

Figure 3: Help or hindrance of the table for determining the criteria of social assistance.
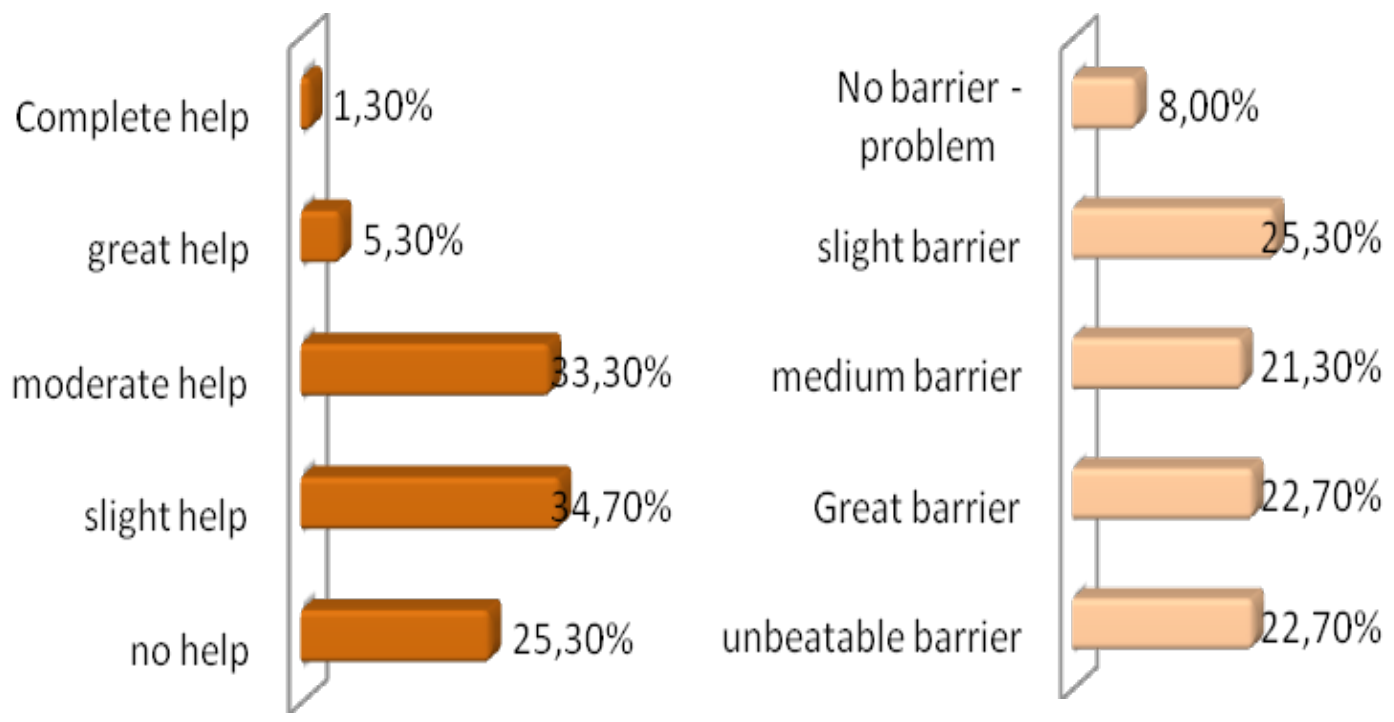

Source: Authors' own research

Figure 3 illustrates the views of hearing-impaired people to the tables of Act 447/2008 Coll. on financial benefits to compensate severe disability.

It turns out that most respondents consider these tables to be a barrier, or ill means of effective assistance. In addition to the questionnaires, we also investigated why the respondents chose their answer, and we learned that some people chose the label of "unbeatable barrier" because they could not get the status of a citizen with severe disabilities or could not obtain approval for a better hearing aid; others understood it as a serious hurdle in the government's officially proclaimed effort to eliminate communication barriers. There were also comments on the obsolescence of categorization according to Fowler (introduced before World War II).

The table in Act 447/2008 Coll. provides the categorization of hearing impairment, or hearing loss according to Fowler. These 
criteria are used to assess the degree of disability and to award certain social benefits or advantages. In connection with hearing aids, it also concerns the possible state aid in buying or servicing hearing aids. According to set criteria, people referred to as hard of hearing are often not eligible to apply for state aid. Generally speaking, they are not "deaf enough". The criteria do not reflect whether it concerns a teacher, lawyer, farmer or a truck driver. They only deal with reduced working capacity. However, in the professions where every word is concerned, for example, the limit of hearing loss of 60$65 \%$ means a significant negative impact on communication. On the other hand, a forest worker with such a hearing impairment would not significantly suffer from reduced working capacity at all. But a teacher would. However, this law does not account for it. Article 7 of Law 447/2008 Coll. states that "impaired communication ability is limited ability to communicate due to impairment or loss of body functions, sensory functions or mental functions." Although the law states that compromised communication abilities are compensated, compensation is provided only to persons with severe disabilities, namely those with $50 \%$ degree of functional disorder or more. The above-mentioned table considers $50 \%$ degree of functional disorder to be a severe hearing loss with a minimum loss of $80 \%$ according to Fowler (practical deafness of more than $85 \%$ according to Fowler and complete deafness of $100 \%$ is considered as a degree of functional disorder of $70 \%$ and $80 \%$ ).

\section{Conclusion}

Based on our preliminary research results, we can reasonably believe that, in the opinion of the respondents, there is room for many options to improve the social policy of the state for citizens with hearing disabilities in the context of eliminating communication barriers. It is important to recognize our finding that people whose hearing is impaired and who do not use sign language to communicate are more likely to rely on high-quality hearing aids than those who use sign language to communicate. However, we have not confirmed this statistically, so we can present this knowledge only as an assumption that will need to be verified by further research. It turns out that the economically weaker people cannot afford the multi-channel devices and, at the same time, are not eligible for state assistance - compensation under Act 447/2008 Coll. And deaf people who prefer to communicate using the sign language, often do not use the hearing aids at all. Although they have a greater chance of getting governmental support, their hearing loss is so great that the use of a hearing aid is of no great importance for them in terms of communication.

\section{References}

1. BENO P (2014) Communication with the hearing impaired in health and social work. In: BENO P, TARCSIOV D, CAPIKOVA $\mathrm{S}$ Communication with hearing impaired in health and social work. Typi Universitatis Tyrnaviensis a VEDA SAV, Trnava, 272 pp. II. extended and refined editions. ISBN 97880-8082-786-1.

2. CERNANOVA A (2012) Mental Disorders in People with Hearing Impairment In Proceeding Communicating with Patients / Clients With Hearing Impairments.Trnava: Typi Universitatis Tyrnaviensis, Trnava, 244 pp. ISBN: 978-80-8082-536-2.

3. GROMA M (2009) Psychological Aspects of Postlingual Hearing Disorder. In Proceeding Communicating with Patients with Hearing Impairment Trnava: Typi Universitatis Tyrnaviensis, Trnava, pp. 82 ISBN 978-80-8082-315-3.

4. ORGONASOVA M, PALAT M (2001) Bratislava: International Classification of 
Functional Disability and Health, MKF, World Health Organisation, 01 ISBN 9241545429.

5. SLOWIK J (2007) Special pedagogy. Praha: Grada Publishing, a.s., 2007. ISBN 97880- 247-1733-3.

6. TARCSIOVA D, HOVORKOVA S (2002) We have a child with a hearing disability, what next? (Handbook for Parents with Hearing Disabilities). Bratislava: EFFETA, ISBN: 80-968584-5-9.

7. Act No. 447/2008 Coll. The Act on Cash Contributions for Compensation of Serious Disabilities and on Amendments to Certain Acts. [online]. [2016-10-23]. Available at: $<$ http://www.zakonypreludi.sk/zz/2008-447. 